\title{
Desdobramentos do Programa Territórios da Cidadania no Nordeste Paraense: desenvolvimento ou controle social?
}

\author{
Outcomes of the Territórios da Cidadania Program in the Nordeste Paraense: \\ development or social control?
}

\begin{abstract}
Desdoblamientos del Programa Territórios da Cidadania en el Nordeste Paraense: desarrollo o control social?
\end{abstract}

Arthur Boscariol da Silva Orientadora: Eliane Tomiasi Paulino Dissertação de Mestrado em Geografia - Universidade Estadual de Londrina

\begin{abstract}
RESUMO: A dissertação teve como objetivo investigar o modelo de desenvolvimento proposto e implantado no Nordeste Paraense pelo Programa Territórios da Cidadania. Para tanto, procedeu-se à análise da concepção do conceito de território subjacente ao Programa, com base em documentação institucional correlata, contrapondo-o ao empregado por autores da Geografia. Na sequência, investigaram-se diferentes concepções de desenvolvimento: liberdade enquanto meio necessário para atingir o desenvolvimento e como finalidade deste; desenvolvimento enquanto maneira de controle social e expansão das relações capitalistas de produção, mediante a criação de expectativas que não se cumprem; desenvolvimento fundamentado na busca de autonomia individual e coletiva, geradora de territórios autônomos. Fundamental para esse exercício foi o trabalho com escalas, partindo-se do contexto internacional no qual se deu a disseminação do discurso de desenvolvimento territorial, correlacionando-o às institucionalidades criadas no Brasil, no âmbito do governo federal que culminaram na criação do Programa Desenvolvimento Sustentável de Territórios Rurais (PRONAT) e do Programa Territórios da Cidadania. Para compreender a implementação deste último, buscou-se no Território Nordeste Paraense as evidências empíricas de como se deu a sua materialização enquanto política pública. Considerando este recorte geográfico, investigou-se mais a fundo as medidas deliberadas pelo colegiado territorial e executadas pelo poder público, discutindo seu alcance e desdobramentos, sem perder de vista a gestão dos bens adquiridos. Para realização do trabalho, utilizou-se material bibliográfico e publicações científicas que tratam de temas como território, desenvolvimento e programas governamentais de abordagem territorial; entrevistas com diversos envolvidos com o Programa e os responsáveis pela gestão dos bens adquiridos; trabalhos de campo para averiguar a situação dos bens adquiridos; e análise documental referente às aquisições e as atas de reuniões do colegiado territorial. A correlação entre teoria e empiria entrelaçadas no plano analítico leva a concluir que o Programa Territórios da Cidadania é primordialmente mais um discurso do desenvolvimento capitalista, fundamentado em promessas que não se cumprem, sendo suas contribuições desproporcionais às suas propostas, gerando muitas expectativas e poucas medidas concretas. Com isso, pode-se afirmar ser este mais um mecanismo de controle social, o que não significa desconsiderar as medidas em si, dada sua importância em face da situação de vulnerabilidade social dos Territórios selecionados.
\end{abstract}


Desdobramentos do Programa Territórios da Cidadania no Nordeste Paraense: desenvolvimento ou...

PALAVRAS-CHAVE: Políticas públicas; Territórios da Cidadania; Nordeste paraense; Desenvolvimento.

ABSTRACT: In the context of the implementation of territorial public policies in Brazil, the Territórios da Cidadania Program is presented as a new form of territorial management based on the delimitation of similar areas, with the participation of organized civil society. The proposal is announced as innovative, however, it follows principles of development previously applied. The official documents that suggest changes in the state actions, but are unaccompanied by the mechanisms that enable its operation. Thus, through the analysis of the Program's operation in the Nordeste Paraense, focusing on its material achievements, the present dissertation sought to unveil the conception of the guiding development of the actions carried out, contrasting its discourse with its practice.

KEYWORDS: Public policy; Territórios da Cidadania; Nordeste Paraense; Development.

RESUMEN: En el contexto de la implementación de las políticas públicas territoriales en Brasil, el Programa Territórios da Cidadania es presentado como una nueva forma de gestión del territorio pautada en la delimitación de áreas similares contando con la participación de la sociedad civil organizada. La propuesta se anuncia como innovadora, sin embargo, acompaña los principios del desarrollo anteriormente aplicado. Los documentos oficiales que sugieren cambios en las acciones estatales, pero son desatendidos de los mecanismos que viabilicen su funcionamiento. Así, a través del análisis funcionamiento del Programa en el territorio Nordeste Paraense, con foco en sus realizaciones materiales, la presente disertación buscó desvelar la concepción de desarrollo orientadora de las acciones realizadas, contraponiendo su discurso a su práctica.

PALABRAS CLAVES: Políticas públicas; Territórios da Cidadania; Nordeste Paraense; Desarrollo.

Pesquisa financiada pela Coordenação de Aperfeiçoamento de Pessoal de Nível Superior (CAPES).

Disponível em: http://www.bibliotecadigital.uel.br/document/?code=vtls000211773

Recebido: abril de 2017. Aceito: agosto de 2017. 